\title{
Absence of effect of maternal immunization to paternal antigens on placental weight, fetal weight and litter size in the mouse
}

\author{
C. M. Hetherington \\ Clinical Research Centre, Watford Road, Harrow, Middlesex HAl 3UJ, U.K.
}

Summary. No evidence was obtained that immunization to paternal antigens affected placental weight, fetal weight or litter size on Day 18 of pregnancy in female mice.

\section{Introduction}

Pregnancy is often regarded as an immunological paradox. Despite the presence of paternal antigens on fetal and placental tissues a mother fails to reject the conceptus, and it has been postulated that the conceptus may be at an advantage when it differs antigenically from the mother (James, 1967). When mice of two inbred strains are mated, placental and fetal weights are usually, but not always, greater than those of within-strain matings (McCarthy, 1965; McLaren, 1965; Hetherington, 1971). Billington (1964) has suggested that this increase in placental weight is a result of the antigenic differences between mother and conceptus. It has also been reported that, when a female mouse is sensitized to the antigens of the stud male, placental and fetal weights are increased relative to those of untreated controls, and that the probability of successful implantation is greater (James, 1965, 1967; Beer, Scott \& Billingham, 1975).

If a conceptus which differs antigenically from its mother has an increased growth potential and a greater chance of survival, an explanation would be provided for the existence of the widespread antigenic polymorphisms (Clarke \& Kirby, 1966). The present study was carried out to determine whether the results of the original experiment of James (1965), involving immunization of female mice to paternal antigens, could be confirmed.

\section{Materials and Methods}

Mice of the $\mathrm{A} / \mathrm{HeLac}\left(\mathrm{H}-2^{\mathrm{a}}\right), \mathrm{C} 57 \mathrm{BL} / 10 \mathrm{ScSnCrc}\left(\mathrm{H}-2^{\mathrm{b}}\right)$ and $\mathrm{CBA} / \mathrm{CaCrc}\left(\mathbf{H}-2^{\mathrm{k}}\right)$ strains were used and are subsequently referred as to A, C57 or CBA animals. At 5 weeks of age females were allocated at random to immunized and control groups. The mice were immunized with 6 weekly intraperitoneal injections of $20-30 \times 10^{6}$ spleen cells obtained from C57 or A-strain male mice. The immunization schedule was started when mice were 5 weeks old and females were placed with the stud males immediately after the 6 th injection. Age-matched mice from the control groups were also mated at this time. Females were checked daily for vaginal plugs and the day of finding a plug was taken as Day 1 of pregnancy.

The mice were killed by cervical dislocation on Day 18 of pregnancy. Placentas and fetuses were dissected free from their membranes, blotted lightly and weighed. The numbers of conceptuses dying during early, middle and late pregnancy were recorded according to the criteria of McLaren \& Michie (1959).

The mean placental and fetal weights were analysed by regression of the $\log _{10}$ values on placental number (the number of live fetuses plus the number of conceptuses dying in middle and late pregnancy), a method shown to be appropriate by Healy, McLaren \& Michie (1960).

\section{Results}

In no instance did immunization to paternal antigens significantly affect placental weight, or fetal weight when allowance was made for differences in litter size (Table 1). There was also no effect of immunization on implantation number or post-implantation survival. 


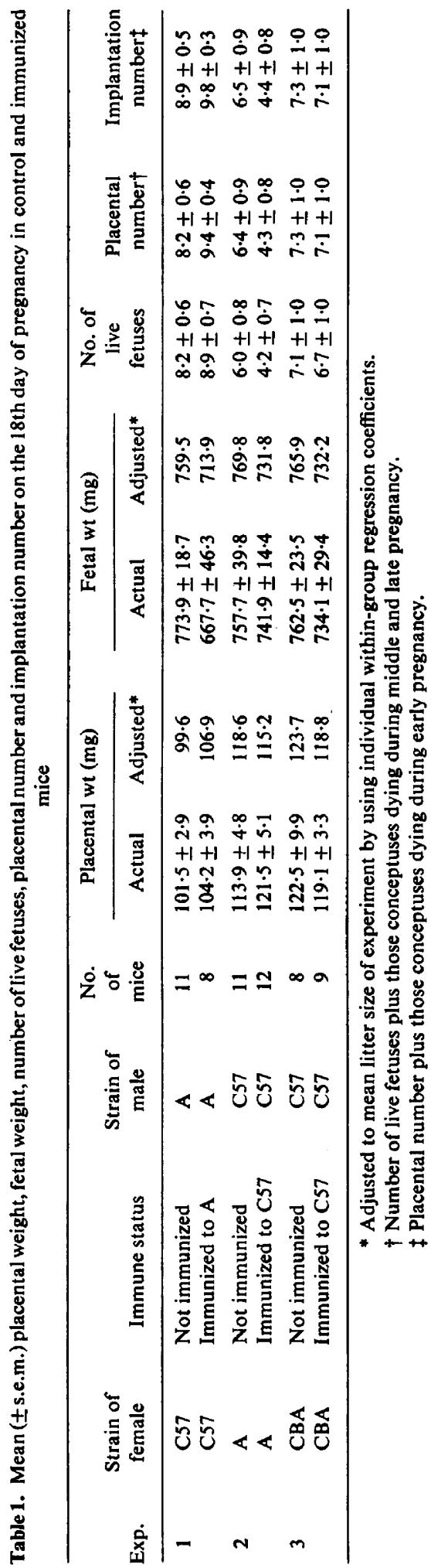


Placental weight, adjusted for differences in litter size was less in the immunized groups of 2 of the 3 experiments, while fetal weight was less in all instances: none of these reductions in weight was statistically significant.

\section{Discussion}

In contrast to the work of James $(1965,1967)$ and Beer et al. (1975) placental weight, fetal weight and litter size were unaffected by maternal immunization to paternal strain antigens. The present work is, however, in agreement with that of Clarke (1971) and Humber, Mahouy, Chinn \& Barnes (1974) who found that maternal immunization to paternal antigens did not significantly affect the course of pregnancy in the mouse. In the present study and that of Clarke (1971), fetal weight tended to be less in immunized animals, although the reduction in weight was not statistically significant. Three independent studies, therefore, have failed to confirm the work of James (1965).

An explanation of these differing results is not immediately apparent. James $(1965,1967)$ and Beer et al. (1975) did not adjust their data for variations in litter size, while the data of Clarke (1971), Humber et al. (1974) and those of the present study were analysed by the regressions of placental and fetal weight on litter size. There were also differences in the strains of mice used. Clarke (1971) used the same strains as James $(1965,1967)$ (C57BL immunized to A2G) in one experiment and the present study used one of the strain combinations employed by Beer et al. (1975) but different sublines (A immunized to C57BL). Humber et al. (1974) used an outbred strain. The methods of immunization also varied. James (1965) used 2 intraperitoneal injections of lymphoid cells while I used 6 injections. Beer et al. (1975) gave 1 skin graft followed by 2 intraperitoneal injections of lymphoid cells, and James (1967) used various schedules of skin grafting and/or intraperitoneal injections. Clarke (1971) also used various immunization schedules involving different numbers of lymphoid cell injections with and without skin grafts, but no differences were found between the various protocols.

In the original egg-transfer experiment of Billington (1964) the results were interpreted to indicate that antigenic dissimilarity between mother and fetus resulted in increased placental weight. The results can also be explained in terms of complementation (Clarke \& Hetherington, 1972; McLaren, 1975 ) whereby the recipient foster strain is able to supply a deficiency present in the donor strain. The reciprocal transfer was not carried out by Billington (1964), but Humber (1976) transferred eggs between CBA and C57BL mice and found no evidence that placental weight was affected by antigenic dissimilarity between mother and conceptus. In addition, the increased placental weight which is usually found with inter-strain matings, and which was considered to support the hypothesis that placental and fetal weight are increased in the presence of antigenic differences, may be readily explained as heterosis (Hetherington, 1971).

If antigenic differences between mother and conceptus do result in increased placental weight, it would be anticipated that tolerance to paternal antigens would result in reduced placental weight. James $(1965,1967)$ and Beer et al. (1975) published data showing such a reduction, but Clarke (1971) and Hetherington \& Fowler (1978) have been unable to confirm these results. Similarly, the report by Beer et al. (1975) that litter size and post-implantation survival are increased when mother and fetus differ antigenically could not be confirmed (Hetherington, Humber \& Clarke, 1976).

There is therefore no incontrovertible evidence currently available to support the suggestion that antigenic differences between mother and conceptus affect placental weight, fetal weight or litter size in the mouse.

\section{References}

Beer, A.E., Scott, J.R. \& Billingham, R.E. (1975) Histocompatibility and maternal immunological status as determinants of fetoplacental weight and litter size in rodents. J. exp. Med. 142, 180-196.

Billington, W.D. (1964) Influences of immunological dissimilarity of mother and foetus on size of placenta in mice. Nature, Lond. 202, 317-318.

Clarke, A.G. (1971) The effects of maternal preimmunization on pregnancy in the mouse. J. Reprod. Fert. 24, 369-375. 
Clarke, A.G. \& Hetherington, C.M. (1972) Immunogenetic aspects of maternal fetal relations. $J$. Reprod. Fert., Suppl. 15, 99-118.

Clarke, B. \& Kirby, D.R.S. (1966) Maintenance of histocompatibility polymorphisms. Nature, Lond. 211, 999-1000.

Healy, M.J.R., Mclaren, A. \& Michie, D. (1960) Fetal growth in the mouse. Proc. $R$. Soc. B 153, 367379.

Hetherington, C.M. (1971) The decidual cell reaction, placental weight, foetal weight and placental morphology in the mouse. J. Reprod. Fert. 25, 417-424.

Hetherington, C.M. \& Fowler, H. (1978) Effect of tolerance to paternal antigens on placental and fetal weight in the mouse. J. Reprod. Fert. 52, 113-117.

Hetherington, C.M., Humber, D.P. \& Clarke, A.G. (1976) Genetic and immunological aspects of litter size in the mouse. J. Immunogenet. 3, 245-252.

HUMBER, D.P. (1976) The immunological consequences of pregnancy. Ph.D. thesis, University College, London.

Humber, D.P., Mahouy, G., Chinn, S. \& Barnes, R.D. (1974) The influence of parity and maternal pre- immunization on fetal survival in mice. $J$. Reprod. Fert. 41, 193-196.

JAMES, D.A. (1965) Effects of antigenic dissimilarity between mother and foetus on placental size in mice. Nature, Lond. 205, 613-614.

JAMES, D.A. (1967) Some effects of immunological factors on gestation in mice. J. Reprod. Fert. 14, 265-275.

MCCARThy, J.C. (1965) Genetic and environmental control of foetal and placental growth in the mouse. Anim. Prod. 7, 347-361.

MCLAREN, A. (1965) Genetic and environmental effects on foetal and placental growth in mice. J. Reprod. Fert. 9, 79-98.

MCLAREN, A. (1975) Antigenic disparity: does it affect placental size, implantation or population genetics? In Immunobiology of Trophoblast, pp. 255-273. Eds R. G. Edwards, C. W. S. Howe \& M. H. Johnson. Cambridge University Press.

MClaren, A. \& Michie, D. (1959) Superpregnancy in the mouse. 1. Implantation and foetal mortality after induced superovulation in females of various ages. J. exp. Biol. 36, 281-300.

Received 9 September 1977 